\title{
Perceived cognitive deficits, emotional distress and disability following whiplash injury
}

\author{
Michael JL Sullivan $\mathrm{PhD}^{1}$, Erin Hall BSc${ }^{2}$, Rosita Bartolacci BSc${ }^{2}$, \\ Maureen E Sullivan $\mathrm{PhD}^{3}$, Heather Adams BSW ${ }^{4}$
}

MJL Sullivan, E Hall, R Bartolacci, ME Sullivan, H Adams. Perceived cognitive deficits, emotional distress and disability following whiplash injury. Pain Res Manage 2002;7(3):120-126.

OBJECTIVES: To describe the pattern of perceived cognitive deficits in patients with whiplash injury, to examine the relation between perceived cognitive deficits and disability, and to examine the determinants of perceived cognitive deficits in patients with whiplash injury.

PARTICIPANTS: A total of 81 individuals participated in the study. There were 29 patients (13 men, 16 women) with a diagnosis of whiplash, grade I or II. Patients with work-related softtissue injuries $(n=24)$ and nonclinical controls $(n=28)$ were included as comparison groups.

METHODS: Participants completed measures of perceived cognitive deficits, pain severity, depression, anxiety and pain-related disability.
RESULTS: Both patient groups scored significantly higher than the nonpatient control group on the measure of perceived cognitive deficits, but did not differ significantly from each other. Perceptions of cognitive deficits were significantly correlated with pain-related disability. A hierarchical regression examining the relative contribution of anxiety, depression and pain showed that only anxiety and depression contributed significant unique variance to the prediction of perceived cognitive deficits.

DISCUSSION: The potential benefits of focusing interventions on the management of anxiety and depression in the rehabilitation of patients with whiplash injuries are discussed.

Key Words: Anxiety; Depression; Perceived cognitive deficits; Whiplash

Résumé à la page suivante

${ }^{1}$ Departments of Psychology and Psychiatry, Dalhousie University; ${ }^{2}$ Department of Psychology, Dalhousie University; ${ }^{3}$ Fenwick Psychological and Health Consultants; ${ }^{4}$ Pain Research Centre, Dalhousie University, Halifax, Nova Scotia

Correspondence and reprints: Dr Michael Sullivan, Dalhousie University Pain Research Centre, 5595 Fenwick Street, Suite 314, Halifax,

Nova Scotia B3H 4J1. Telephone 902-422-4605, fax 902-421-1292, e-mail sully@is.dal.ca 


\section{Troubles cognitifs subjectifs, troubles émotifs et incapacité par suite d'une entorse cervicale}

OBJECTIFS : Dresser le tableau des troubles cognitifs subjectifs chez les patients qui ont subi une entorse cervicale afin d'examiner le lien entre ces troubles et l'incapacité; étudier les déterminants des troubles cognitifs subjectifs chez ces patients.

PARTICIPANTS : Au total, 81 personnes ont participé à l'étude : 29 patients (13 hommes et 16 femmes) ayant subi une entorse cervicale de classe I ou II, 24 patients ayant subi des lésions des tissus mous au travail et 28 témoins sans antécédents cliniques à des fins comparatives.

MÉTHODE : On a procédé à une évaluation des troubles cognitifs sub- jectifs, de la douleur, de la dépression, de l'anxiété et de l'incapacité liée à la douleur chez tous les participants.

RÉSULTATS : Les résultats de l'évaluation des troubles cognitifs subjectifs ont été significativement plus élevés dans les deux groupes de patients que dans le groupe témoin, mais la différence entre les deux premiers groupes était plutôt faible. Il semble exister une étroite corrélation entre les troubles cognitifs subjectifs et l'incapacité liée à la douleur. Une régression hiérarchique visant à examiner le poids relatif de l'anxiété, de la dépression et de la douleur a révélé que seules l'anxiété et la dépression constituaient une variance unique significative de la prédiction des troubles cognitifs subjectifs.

DISCUSSION : Les avantages potentiels des interventions de réadaptation axées sur le traitement de l'anxiété et de la dépression chez les patients ayant subi une entorse cervicale font ici l'objet de discussion.
$\mathrm{I}^{\mathrm{n}}$ ndividuals who have sustained whiplash injuries frequently report a host of symptoms, including pain, headaches, dizziness, nausea, vertigo, anxiety and depression. Postwhiplash symptoms can persist for months, and sometimes years, contributing significantly to social and occupational disability (1). The cost of compensation for disability related to whiplash has been escalating, accounting for as many as $75 \%$ of injury claims following motor vehicle accidents $(2,3)$. The factors that contribute to enduring disability following whiplash injury remain poorly understood. One of the objectives of the present study was to explore the relation between perceived cognitive deficits and disability in patients with whiplash injury.

\section{WHIPLASH INJURIES AND COGNITIVE DIFFICULTIES}

Whiplash injuries result from incidents in which the head and neck are exposed to sudden changes in velocity (4). Rear-end motor vehicle accidents are one of the primary causes of whiplash injury in North America (5-7). Although there is some debate concerning the precise mechanisms of whiplash injuries, for a significant proportion of individuals, symptoms of physical and emotional distress may persist for several months, even in the absence of objective signs of tissue pathology. In a minority of patients, symptoms of whiplash may result in permanent disability $(3,8,9)$.

Individuals who have sustained whiplash injuries frequently report cognitive difficulties $(6,10,11)$. These may include concentration difficulties, memory problems and distractibility (9). The basis for perceptions of cognitive difficulties in patients with whiplash remains unclear. Several investigators have used objective measures of cognitive function to explore the possibility that accident-related neural damage may compromise cognitive functioning $(9,12)$. The findings have been mixed. In severe cases of whiplash, there are indications that the injury may result in significant and measurable cognitive impairment $(13,14)$. However, other studies have failed to reveal evidence of significant cognitive dysfunction following whiplash injury, and still others have questioned whether observed cognitive dysfunction can be attributed to injury-related neural damage $(6,9,10,12,13,15)$.

Several explanations have been put forward to account for the association between whiplash injury and cognitive difficulties. Cognitive difficulties following whiplash injury may be due to the attention-disrupting effects of pain as opposed to neural damage $(16,17)$. Radanov et al (12) examined the relation between neuroimaging findings and cognitive performance deficits in patients with whiplash injury. The findings revealed no evidence of an association between indexes of neural dysfunction and cognitive test performance. However, there were indications that pain intensity and anxiety interfered with performance on tests of divided attention. It has also been suggested that medication side effects, current life stress and psychosocial distress may contribute to cognitive difficulties in patients with whiplash injuries $(5,6,9,15,18,19)$.

Regardless of the basis for cognitive difficulties following whiplash injury, one's perception of cognitive deficits may have important implications for day to day functioning. Individuals who perceive themselves as having problems with concentration and memory may be less confident in their ability to perform tasks that require these abilities. Consequently, they may be less likely to engage in social, recreational or occupational activities. In other words, it is possible that individuals who perceive themselves as having cognitive deficits may be more disabled than individuals who do not perceive themselves as having cognitive deficits $(9,10)$.

Little is known about the relation between perceived cognitive difficulties and disability in patients who have sustained whiplash injuries. First, it is unclear whether individuals with whiplash injuries perceive themselves as experiencing difficulties in all domains of information processing or whether their perceptions of cognitive difficulties are restricted to specific domains (eg, attention, memory, planning). Furthermore, it is not known whether differences in the nature of perceived cognitive difficulties are associated with differences in level of disability. Finally, 
the factors that give rise to the perception of cognitive difficulties in patients with whiplash injuries have not been systematically investigated.

Increased understanding of the relation between perceived cognitive difficulties and disability in patients who have sustained whiplash injuries may have significant clinical implications. Demonstrating a relation between perceived cognitive difficulties and disability would suggest that the effective management of cognitive difficulties might facilitate progress in the rehabilitation of patients with whiplash injuries. In addition, elucidation of the factors that give rise to the perception of cognitive difficulties following whiplash injury may point to useful targets of intervention that would allow treatment programs to be tailored to the needs of the specific patient.

\section{THE PRESENT RESEARCH}

The present study had three major objectives: to describe the pattern of perceived cognitive deficits in patients with whiplash injury, to examine the relation between perceived cognitive deficits and disability, and to examine the determinants of perceived cognitive deficits in patients with whiplash injury.

To address the first objective, patients with whiplash injuries were asked to complete the perceived deficits questionnaire (PDQ) (20). The PDQ is a measure of perceived cognitive difficulties that yields subscale scores for four different domains of information processing: attention/concentration, planning/organization, retrospective memory and prospective memory. The second objective of the study was addressed by examining the relation between the PDQ subscales and an index of pain-related disability. In previous studies of patients suffering from demyelinating disease, high scores on the PDQ have been associated with a higher probability of unemployment (21).

The responses of patients with whiplash injuries were compared with those of a matched sample of patients who were experiencing persistent pain subsequent to a workrelated soft-tissue injury and a matched sample of pain-free controls. These comparisons permitted the examination of questions concerning the role of the mechanism of injury as the determinant of perceived cognitive difficulties.

All participants also completed measures of pain intensity, depression and anxiety. Analyses were then performed to examine the degree to which these variables were associated with perceptions of cognitive deficits. These variables were chosen on the basis of previous research showing that pain intensity, depression and anxiety can be significant determinants of cognitive performance deficits $(19,22-24)$.

\section{Participants}

\section{SUBJECTS AND METHODS}

A total of 81 individuals participated in the study. The group of primary interest comprised 29 patients (13 men, 16 women) with whiplash, grade I or II, diagnosed according to the criteria of Spitzer et al (3). Patients who showed radiographic evidence of vertebral fracture, or clinical signs of nerve root compression, concussion or head trauma were not considered for participation. All patients with whiplash were consecutively referred to the Atlantic Pain Clinic, Halifax, Nova Scotia, a multidisciplinary centre specializing in the treatment of persistent pain disorders. A second group of patients with musculoskeletal injuries $(n=24)$ consequent to work-related, nonimpact strains or sprains served as a comparison group. The patients with workrelated injuries were drawn from clinic files and were matched to whiplash patients with respect to sex, age (within three years), education (within years), years after injury (within one year) and physical demands of occupation. A nonclinical comparison group was also included $(n=28)$. The latter group consisted of individuals who were currently employed in local industry and were not currently seeking help for pain-related difficulties. Nonpatient volunteers were recruited until the sample could be matched to the whiplash and work-related injury groups on all variables noted above except duration of pain.

\section{Procedure}

Participants completed the measures of perceived cognitive deficits, depression, pain and disability during their initial visit to the Atlantic Pain Clinic. All patients in the whiplash group were currently involved in litigation, and all patients in the work-related injury group were currently receiving worker's compensation benefits. Participants were aware that the information collected was confidential and would only be reported in aggregate form.

\section{Measures}

Perceived cognitive deficits: The PDQ (20) was used to assess patients' subjective complaints of cognitive difficulties. The PDQ consists of 20 questions assessing four dimensions of perceived cognitive difficulties: attention/ concentration (ie, "I lose my train of thought when I am speaking"), planning/organization (ie, "I have trouble getting things organized"), retrospective memory (ie, "I don't remember what I did last weekend") and prospective memory (ie, "I forget what I came into the room for"). Respondents are asked to rate the frequency of occurrence of each cognitive difficulty on a five-point scale with the end points 'never' (score of 0 ) and 'almost always' (score of 4). Previous research has shown the PDQ to be internally reliable (alpha 0.78 to 0.84 ) and to be related to occupational disability $(20,21)$.

Depression: The Beck Depression Inventory (BDI) (25) was used as a self-report measure of depression. The BDI consists of 21 items describing various symptoms of depression. Subjects' responses were summed to yield an overall index of severity of depressive symptoms. The BDI has been shown to be a reliable and valid index of depressive symptoms in patients suffering from persistent pain (26).

Anxiety: The State-Trait Anxiety Inventory - Trait Form (STAI-T) (27) was used to measure trait anxiety. Subjects were asked to rate the frequency with which they experienced each of 20 symptoms of anxiety on a four-point scale 
TABLE 1

Means and standard deviations for demographic and pain-related variables

\begin{tabular}{lccc}
\hline & Whiplash & $\begin{array}{c}\text { Work-related } \\
\text { injury }\end{array}$ & Control \\
\hline Mean age, years (SD) & $34.5(9.1)$ & $36.8(9.6)$ & $34.4(9.1)$ \\
Men/women & $13 / 16$ & $13 / 16$ & $13 / 16$ \\
$\begin{array}{l}\text { Mean years of } \\
\text { education (SD) }\end{array}$ & $13.4(3.2)$ & $12.9(3.4)$ & $13.8(3.0)$ \\
Mean years after injury (SD) & $3.4(3.8)$ & $3.2(3.6)$ & \\
Mean MPQ PRI score (SD) & $41.7(15.4)$ & $39.6(14.7)$ & $18.5(12.7)$
\end{tabular}

MPQ PRI McGill Pain Questionnaire Pain Rating Index

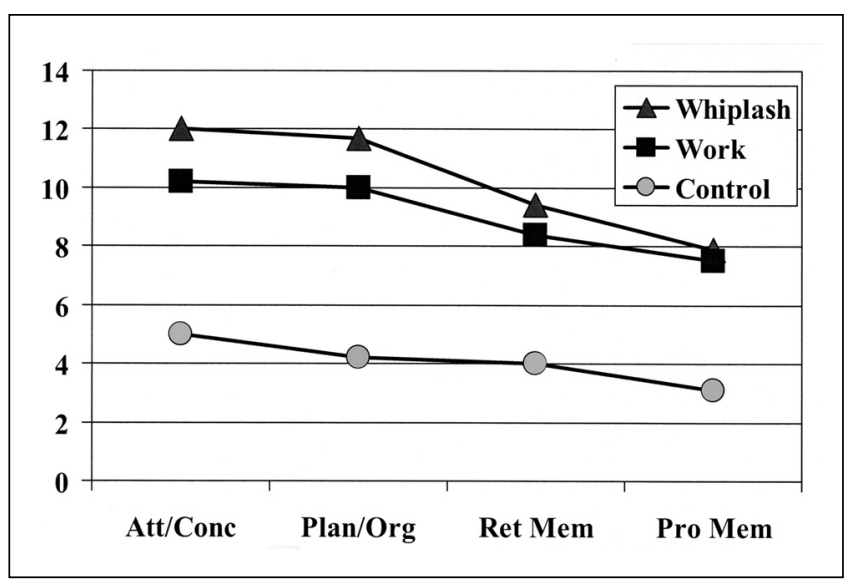

Figure 1) Perceived cognitive deficits in patients with whiplash injuries or work-related musculoskeletal injuries, and nonpatient controls. Att/Conc Attention/concentration; Plan/Org Planning/organization; Pro Mem Prospective memory; Ret Mem Retrospective memory

with the end points 'almost never' (score of 1) and 'always' (score of 4). Participants' responses were summed to yield a composite index of trait anxiety.

Pain: The McGill Pain Questionnaire (MPQ) (28) was used to assess pain. Participants were asked to endorse adjectives that best described their current pain experience. The Pain Rating Index (PRI) is a weighted sum of all adjectives endorsed, and is considered to be one of the more reliable and valid indexes of an individual's pain experience (29).

Disability: The Pain Disability Index (PDI) (30) was used to assess the degree to which subjects experienced painrelated disability in seven different areas of daily living (home, social, recreational, occupational, sexual, self-care, life-support). For each life domain, participants were asked to provide disability ratings on 11-point scales with the end points 'no disability' (score of 0 ) and 'total disability' (score of 10 ). The PDI has been shown to be internally reliable and significantly correlated with objective indexes of disability (30).
TABLE 2

The relations among domains of perceived cognitive deficits, and measures of pain, depression, anxiety and disability

\begin{tabular}{cccccccc}
\hline & PDQ-AT & PDQ-PL & PDQ-RE & PDQ-PR & MPQ & BDI & STAI-T \\
\hline PDI & 0.65 & 0.63 & 0.57 & 0.54 & 0.66 & 0.74 & 0.65 \\
\hline
\end{tabular}

BDI Beck Depression Inventory; MPQ McGill Pain Questionnaire (Pain Rating Index); PDI Pain Disability Index; PDQ-AT Perceived deficits questionnaire attention/concentration; $P D Q-P L$ Perceived deficits questionnaire - planning/organization; PDQ-PR Perceived deficits questionnaire prospective memory; PDQ-RE Perceived deficits questionnaire - retrospective memory; STAI-T State-Trait Anxiety Inventory - Trait Form. All $P<0.01$

\section{RESULTS}

Means and standard deviations for the demographic variables and pain-related variables are presented in Table 1 . The mean age of the sample and the pain severity scores are similar to those that have been reported in previous studies of pain and disability in patients with persistent pain disorders $(26,29)$.

Group means for the four different subscales of the PDQ are presented in Figure 1. MANOVA revealed a significant main effect for group (whiplash, work injury, non-patient), $\left(\mathrm{F}_{\text {Wilks Lambda }}[8,150]=6.1 ; \mathrm{P}<0.001\right)$. Follow-up univariate analyses revealed significant group differences for all subscales of the PDQ; attention/concentration $(F[2,78]=23.7$; $\mathrm{P}<0.001)$, planning/organization $(\mathrm{F}[2,78]=25.1, \mathrm{P}<0.001)$, retrospective memory $(\mathrm{F}[2,78]=12.0 ; \quad \mathrm{P}<0.001)$ and prospective memory $(\mathrm{F}[2,78]=14.2 ; \mathrm{P}<0.001)$. Multiple comparisons using the Newman Keuls procedure revealed that patients with whiplash injuries and patients with workrelated injuries scored significantly higher than the nonpatient control subjects on all subscales of the PDQ. The whiplash and work injury groups did not differ significantly on any of the PDQ subscales.

Correlational analyses were conducted to examine the relations among the PDQ subscales; measures of pain, depression and anxiety; and the index of pain-related disability. All subscales of the PDQ were significantly correlated with the measure of pain-related disability (range 0.54 to 0.74 , all $\mathrm{P}<0.01$ ) (Table 2). The magnitude of the relation between perceived cognitive deficits and pain-related disability was comparable with that of more familiar predictors of pain-related disability such as pain severity, depression and anxiety.

Correlational analyses were also conducted to explore the determinants of perceived cognitive deficits. Measures of depression and anxiety were significantly correlated with all subscales of the PDQ (range 0.60 to 0.77 , all $\mathrm{P}<0.01$ ) (Table 3). Pain severity also correlated significantly with the PDQ subscales, but to a lesser degree.

A hierarchical regression was conducted to examine the relative contributions of depression, anxiety and pain to the prediction of perceived cognitive deficits. For this analysis, the four subscales of the PDQ were summed to yield a composite index of perceived cognitive deficits. Age and group 
TABLE 3

Correlates of perceived cognitive deficits

\begin{tabular}{lcccc}
\hline & PDQ-AT & PDQ-PL & PDQ-RE & PDQ-PR \\
\hline MPQ & 0.47 & 0.43 & 0.40 & 0.32 \\
BDI & 0.72 & 0.74 & 0.60 & 0.61 \\
STAI-T & 0.68 & 0.77 & 0.60 & 0.65 \\
\hline
\end{tabular}

BDI Beck Depression Inventory; MPQ McGill Pain Questionnaire (Pain Rating Index); PDQ-AT Perceived deficits questionnaire - attention/concentration; $P D Q-P L$ Perceived deficits questionnaire - planning/organization; $P D Q-$ $P R$ Perceived deficits questionnaire - prospective memory; $P D Q$ RE Perceived deficits questionnaire - retrospective memory STAI-T State-Trait Anxiety Inventory - Trait Form. All P<0.01

(whiplash/work-related injury/control) were entered in step 1 of the analysis and contributed significantly to the prediction of perceived cognitive deficits $\left(\mathrm{R}^{2}=0.25, \mathrm{P}<0.001\right)$ (Table 4). The MPQ, the BDI and the STAI-T were entered in step 2 of the analysis and contributed an additional $28 \%$ of variance to the prediction of perceived cognitive deficits. Examination of the beta weights indicated that, in the final regression equation, only trait anxiety and depression contributed significant unique variance to the prediction of perceived cognitive deficits.

\section{DISCUSSION}

The findings of the present study are consistent with previous empirical and anecdotal studies suggesting that patients with whiplash injuries report significant cognitive difficulties $(9,15)$. The findings suggest that perception of cognitive difficulties may be an important determinant of disability in patients with whiplash injuries. Analyses revealed that perceived cognitive difficulties were significantly correlated with self-reported disability, and the magnitude of the relation between perceived cognitive deficits and disability was comparable with that observed for pain, depression and anxiety. The perceived cognitive difficulties of patients with whiplash injuries were not specific to a particular domain of information processing, but were apparent in all four domains assessed by the PDQ. These findings indicate that the perception of cognitive difficulties is a central feature of the phenomenon of whiplash injury.

In previous research, investigators have raised questions concerning the underlying basis of perceived cognitive deficits following whiplash $(12,15)$. It has been suggested that processes related to psychological distress, as opposed to neural damage, may form the basis of perceptions of cognitive deficits following whiplash. Although the present study did not include objective measures of cognitive dysfunction, the comparison of whiplash patients with patients who suffered from nonimpact strain or sprain injuries provided a vehicle for examining whether the perceived cognitive deficits of whiplash patients could be attributed to factors related to the mechanism of injury. The absence of significant differences in perceived cognitive deficits between patients with whiplash injuries and patients with work-related injuries suggests that the mechanism of injury,

\begin{tabular}{|c|c|c|c|c|}
\hline Variables & Beta & $\mathrm{R}^{2}$ & F(change) & $\mathbf{P}$ \\
\hline \multicolumn{5}{|l|}{ Step 1} \\
\hline Age & -0.06 & & & \\
\hline Group* & -0.03 & 0.25 & $13.0(2,78)$ & 0.001 \\
\hline \multicolumn{5}{|l|}{ Step 2} \\
\hline$M P Q$ & 0.06 & & & \\
\hline $\mathrm{BDI}$ & $0.35^{\dagger}$ & & & \\
\hline STAI-T & $0.39^{\dagger}$ & 0.58 & 20.4 & 0.001 \\
\hline
\end{tabular}

Beta weights are from the final regression analysis. *Whiplash/work-related injury versus control; ${ }^{\dagger} P<0.01$. BDI Beck Depression Inventory; MPQ McGill Pain Questionnaire (Pain Rating Index); STAI-T State-Trait Anxiety InventoryTrait Form

or associated neural damage, is unlikely to be the basis of perceived cognitive deficits following whiplash injury. It is interesting to note that, in previous studies using objective assessment of cognitive difficulties, patients with whiplash injuries have not differed significantly from patients who were suffering from pain conditions unrelated to whiplash $(31,32)$

It has been suggested by numerous investigators that pain severity may be a contributing factor to cognitive problems in patients with whiplash or other persistent pain conditions $(16,17)$. The findings of the present study support this view; zero order correlations revealed significant relations between pain severity and the different subscales of the PDQ. However, the pattern of findings indicates that pain is not the primary determinant of perceived cognitive deficits in patients with whiplash injuries. In the regression analysis, pain did not contribute to the prediction of perceived cognitive deficits over and above the variance accounted for by anxiety and depression. Anxiety and depression each contributed significant unique variance to the prediction of perceived cognitive deficits.

High rates of depression and anxiety have been observed in patients with whiplash injuries $(9,33)$. These symptoms of emotional distress do not appear to be restricted to whiplash patients but are apparent in groups of patients suffering from a variety of persistent pain disorders (34-36). Although several clinicians and investigators have called for more attention to the detection and treatment of emotional dysfunction in persistent pain sufferers, the relation between emotional dysfunction and perceived cognitive deficits has received little attention (37). The findings of the present study suggest that emotional dysfunction may be a central variable underlying perceptions of cognitive deficits following whiplash injury. It is possible that the perception of cognitive deficits may be one of the processes through which emotional distress states, such as anxiety or depression, may affect disability.

Previous research on perceived cognitive deficits has revealed significant relations with aging and depression $(23,38)$. With respect to aging, it has been suggested that 
neural degeneration may form the basis of observed cognitive decline (38). With respect to depression, it has been suggested that motivational deficits or depletion of available cognitive resources may contribute to cognitive difficulties (39). However, these explanations have been put forward to account for 'objective' signs of cognitive impairment as opposed to perceived cognitive deficits.

Available research suggests that perceptions of cognitive deficits are rarely associated with objectively measured cognitive impairment $(40,41)$. The dissociation between these different indexes of cognitive difficulties raises the possibility that objective and subjective cognitive deficits may arise as a function of separate and distinct processes. For example, it has been suggested that the relation between depression and complaints of cognitive difficulties may be a reflection of self-deprecating cognitions that are a central component of depression (23). In other words, depression may lead individuals to rate negatively several domains of their lives, including their cognitive function, even when no actual impairment exists. Future research will need to address the tenability of this explanation.

In the present study, anxiety contributed to the perception of cognitive deficits beyond the variance accounted for by depression. Thus, depression-based self-deprecating thinking is not the sole basis of perceived cognitive deficits in patients with whiplash. Furthermore, it is not possible to appeal to a general 'distress factor' in explaining the basis of perceived cognitive deficits in patients with whiplash. The relation between anxiety and perceived cognitive deficits has not been investigated or discussed extensively. It is possible to speculate that cognitive correlates of anxiety such as selective attention to anxiety-related cues or rumination may play a role $(42,43)$.

Anxiety may focus attention on pain-related information such as diagnostic uncertainty or fear of re-injury, and interfere with an individual's ability to attend to information relevant to everyday activities of living (37). As such, anxiety may contribute to a subjective sense of distractibility.

There are clinical implications to the present findings. Even though perceived cognitive deficits have not been shown to have a strong relation to objectively measured cognitive function, subjective reports of cognitive difficulties remain the primary basis for referring patients with whiplash for the assessment of cognitive dysfunction. Neuropsychological evaluation is a time-consuming and costly form of assessment. The data that have emerged in previous research, as well as in the current study, suggest that subjective complaints of cognitive difficulties may best be interpreted as a sign of emotional distress as opposed to a sign of potential brain damage.

The findings call for greater attention to the early diagnosis and treatment of anxiety and depression following whiplash injury. Pharmacological and psychotherapeutic interventions for depression and anxiety show high rates of success, yet there are indications that a significant proportion of pain patients with diagnosable mood disturbance go untreated or are undertreated (35). In addition to the man- agement of symptoms of depression and anxiety, patients with whiplash injuries may benefit from interventions geared toward minimizing the negative impact of cognitive difficulties. Strategies such as note taking, activity recording and activity structuring can be easily implemented and have been shown to be useful in compensating for cognitive difficulties (20).

Several limitations to the present study call for caution in the interpretation of the findings. First, no objective measures of cognitive function were used, thus precluding any definitive statements about the relation between perceived and objective cognitive problems. In addition, because the design of the study was correlational, the direction of causality remains ambiguous. Research using more sensitive measures of attention, processing speed or processing efficiency may yield interesting insights into the mechanisms underlying the relation between depression, anxiety and perceived cognitive deficits.

The relation between perceived cognitive deficits and disability also requires further investigation. In the present study, disability was assessed through self-report and may not accurately reflect the nature of the association between perceived cognitive deficits and actual disability. In future research, it will be of interest to examine further the variables through which perceived cognitive deficits affect disability. These may include individuals' lack of confidence in their ability to carry out cognitively demanding activities, esteem-related factors such as fear of failure or threatrelated factors such as fear of re-injury. The elucidation of these mediating variables may point to additional targets for intervention.

If replicated with more objective indexes of cognitive function and disability, the data would argue for a reconsideration of the manner in which subjective complaints of cognitive difficulties are managed in the clinical setting. It is possible that increasing the availability of resources for the early assessment of anxiety and depression following whiplash injury may decrease patients' perceptions of cognitive difficulties and, in turn, reduce the degree of disability that they will experience.

ACKNOWLEDGEMENTS: The authors thank Dr Dean Tripp and Nancy Comeau for helpful comments on a previous version of this paper. Portions of this work were presented at the Annual Meeting of the Canadian Pain Society, Banff, Alberta, May 11 to 13, 2000. This research was supported by grants from the Social Sciences and Humanities Research Council of Canada, the Canadian Institutes for Health Research and the Atlantic Pain Clinic.

\section{REFERENCES}

1. Gunzburg R, Szpalski M. Whiplash Injuries: Current Concepts in Prevention, Diagnosis and Treatment of Cervical Whiplash Syndrome. New York: Lippincott-Raven, 1997.

2. Galasko CSB, Murray PM, Pitcher M, et al. Neck sprains after road traffic accidents: a modern epidemic. Injury 1993;24:155-7.

3. Spitzer WO, Skovron ML, Salmi LR. Scientific monograph of the Quebec task force on whiplash associated disorders: redefining whiplash and its management. Spine 1995;20(8 Suppl):1S-73S. 
4. Croft AC. Low speed rear impact collisions: in search of an injury threshold. In: Allen ME, ed. Musculoskeletal Pain Emanating from the Head and Neck: Current Concepts in Diagnosis, Management and Cost Containment. London: Haworth Press, 1996:39-46.

5. Ferrari R, Russell AS. Epidemiology of whiplash: an international dilemma. Ann Rheum Dis 1999;58:1-5.

6. Alexander MP. In the pursuit of proof of brain damage after whiplash injury. Neurology 1998;51:336-40.

7. Stovner LJ. The nosologic status of the whiplash syndrome: a critical review based on a methodological approach. Spine 1996;23:2735-46.

8. Pearce JMS. Whiplash injury: a reappraisal. J Neurol Neurosurg Psychiatry 1989;52:1329-31.

9. Radanov BP, Di Stefano G, Schnidrig A, Sturzenegger M, Augustiny KF. Cognitive functioning after common whiplash. Arch Neurol 1993;50:87-91.

10. Borchgrevink GE, Kaasa A, McDonagh D, Stiles TC, Haraldseth O, Lereim I. Acute treatment of whiplash neck sprain injuries: a randomized trial of treatment during the first 14 days after a car accident. Spine 1998;23:25-31.

11. Ettlin TM, Kischka U, Reichmann S, et al. Cerebral symptoms after whiplash injury of the neck: a prospective and neuropsychological study of whiplash injury. J Neurol Neurosurg Psychiatry 1992;55:943-8.

12. Radanov BP, Bicik I, Dvorak J, Antinnes J, von Schulthess GK, Buck A. Relation between neuropsychological and neuroimaging findings in patients with late whiplash syndrome. J Neurol Neurosurg Psychiatry 1999;66:485-9.

13. Schmand B, Lindeboom J, Schagen S, Heijt R, Koene T, Hamburger HL. Cognitive complaints in patients after whiplash injury: the impact of malingering. J Neurol Neurosurg Psychiatry 1998;64:339-43.

14. Schwartz DP, Barth JT, Dane JR, Drenan SE, DeGood DE, Rowlingson JC. Cognitive deficits in pain patients with and without history of head/neck injury: development of a brief screening battery. Clin J Pain 1987;3:94-101.

15. Smed A. Cognitive function and distress after common whiplash injury. Acta Neurol Scand 1997;95:73-80.

16. Grigsby J, Rosenberg NL, Busenbark D. Chronic pain is associated with deficits in information processing. Percept Mot Skills 1995;81:403-10.

17. Taylor AE, Cox CA, Mailis A. Persistent neuropsychological deficits following whiplash: evidence for chronic mild traumatic brain injury? Arch Phys Med Rehabil 1996;77:529-35.

18. Jamison RN, Sbrocco T, Parris WCV. The influence of problems with concentration and memory on emotional distress and daily activities in chronic pain patients. Int J Psychiatry Med 1988;18:183-91.

19. Kewman DG, Vaishampayan N, Zald D, Han B. Cognitive impairment in musculoskeletal pain patients. Int J Psychiatry Med 1991;21:253-62

20. Sullivan MJL, Edgley K, Dehoux E. A survey of multiple sclerosis. Part I: perceived cognitive problems and compensatory strategy use. Can J Rehabil 1990;4:99-105.

21. Edgley K, Sullivan MJL, Dehoux E. A survey of multiple sclerosis. Part II: determinants of employment status. Can J Rehabil 1991;4:127-32.

22. Eccleston C, Crombez G. Pain demands attention: a cognitiveaffective model of the interruptive function of pain. Psychol Bull 1999;125:356-66.
23. Williams JM, Little MM, Scates S, Blockman N. Memory complaints and abilities among depressed older adults. J Consult Clin Psychol 1986;55:595-8.

24. Johnson MH, Magaro PA. Effects of mood and severity on memory processes in depression and mania. Psychol Bull 1986;101:28-40.

25. Beck AT, Ward CH, Mendelson M, Mock J, Erlbaugh J. An inventory for measuring depression. Arch Gen Psychiatry 1961;4:53-6.

26. Bishop SR, Edgley K, Fisher R, Sullivan MJL. Screening for depression in chronic low back pain with the Beck Depression Inventory. Can J Rehabil 1993;7:143-8.

27. Spielberger CD, Gorsuch RL, Lushene RE. STAI: Manual for the State - Trait Anxiety Inventory. Palo Alto: Consulting Psychologists Press, 1970.

28. Melzack R. The McGill Pain Questionnaire: major properties and scoring methods. Pain 1975;1:277-99.

29. Turk DC, Rudy TE, Salovey P. The McGill Pain Questionnaire reconsidered: confirming the factor analysis and examining appropriate uses. Pain 1985;21:385-97.

30. Tait RC, Chibnall JT, Krause S. The Pain Disability Index: psychometric properties. Pain 1990;40:171-82.

31. Olsness BT. Neurobehavioral findings in whiplash patients with long lasting symptoms. Acta Neurol Scand 1989;30:584-8.

32. Radanov BP, Hirlinger I, Di Stephano G, Valach L. Attentional processing in cervical spine syndromes. Acta Neurol Scand 1992;85:358-62.

33. Lee J, Giles K, Drummond PD. Psychological disturbances and an exaggerated response to pain in patients with whiplash injury. J Psychosom Res 1993;37:105-10.

34. Banks SM, Kerns RD. Explaining high rates of depression in chronic pain: A diathesis-stress framework. Psychol Bull 1996;119:95-110.

35. Sullivan MJL, Reesor K, Mikail S, Fisher R. The treatment of depression in chronic low back pain: review and recommendations. Pain 1992;50:5-13.

36. Asmundson GJG, Norton GR, Allerdings, MD. Fear and avoidance in dysfunctional chronic back pain patients. Pain 1997;69:231-6.

37. Schnurr RF, MacDonald MR. Memory complaints in chronic pain. Clin J Pain 1995;11:103-11.

38. Gilewski MJ, Zelinski EM. Questionnaire assessment of memory complaints. In: Poon LW, ed. Handbook for Clinical Memory Assessment of Older Adults. Washington: American Psychological Association, 1986:93-107.

39. Hasher L, Zacks RT. Automatic and effortful processes in memory. J Exp Psychol Gen 1979;108:356-88.

40. Hermann DJ. Questionnaires about memory. In: Harris JE, Morris PE, eds. Everyday Memory, Actions, and Absent-Mindedness. New York: Academic Press, 1984:133-152.

41. Morris PE. The validity of subjective reports on memory. In: Harris JE, Morris PE, eds. Everyday Memory, Actions, and Absent Mindedness. New York: Academic Press, 1984:153-172.

42. Burkovec TD, Inz J. The nature of worry in generalized anxiety disorder: predominance of thought activity. Behav Res Ther 1990;28:153-8.

43. Mathews A, May J, Mogg K, Eysenck M. Attentional bias in anxiety: selective search or defective filtering. J Abnorm Psychol 1991;99:163-73. 


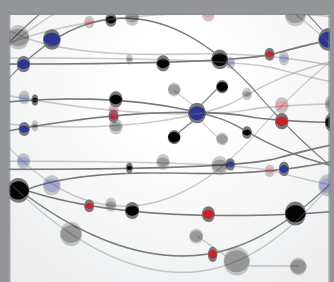

The Scientific World Journal
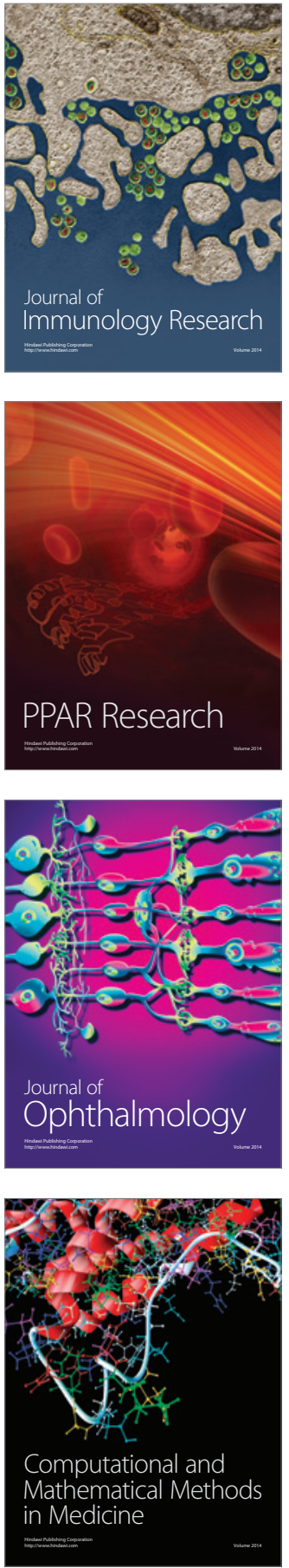

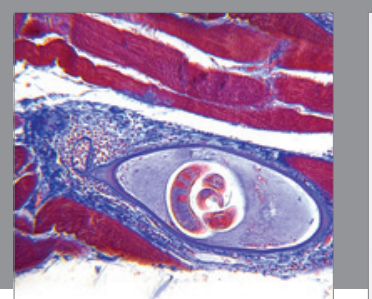

Gastroenterology Research and Practice

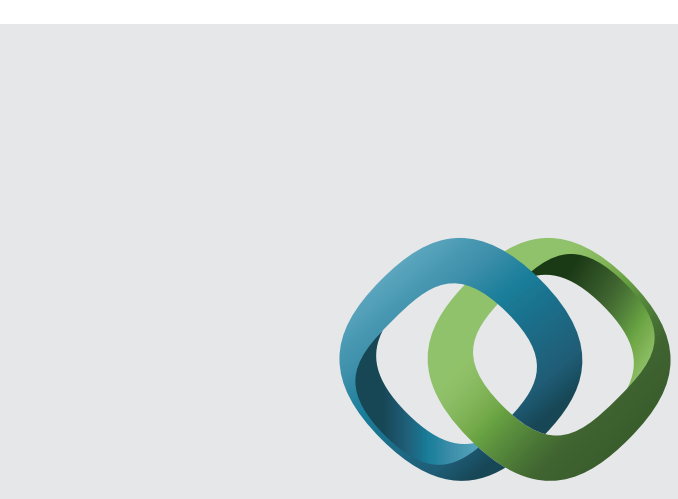

\section{Hindawi}

Submit your manuscripts at

http://www.hindawi.com
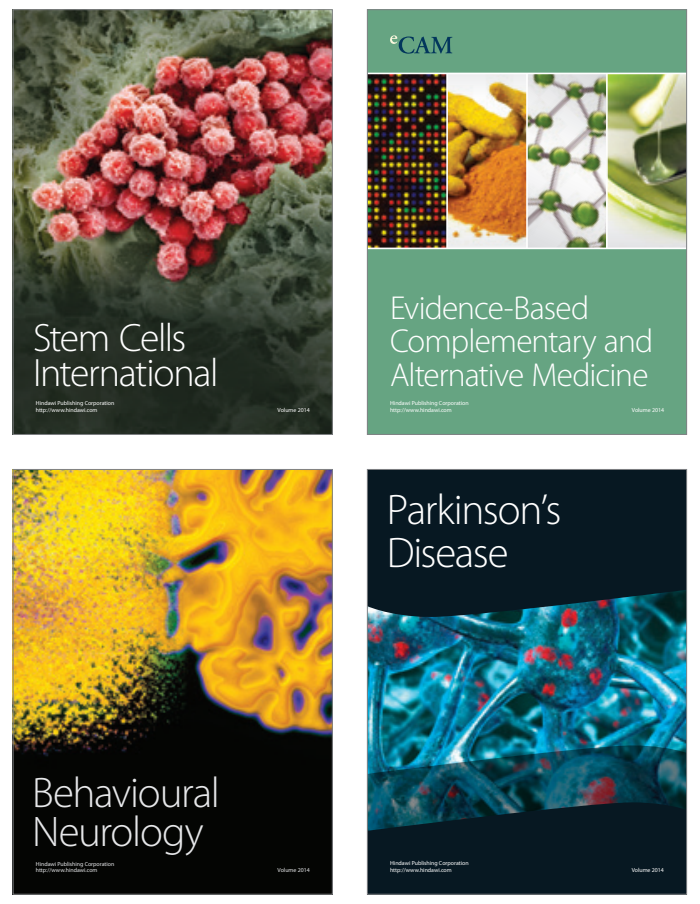
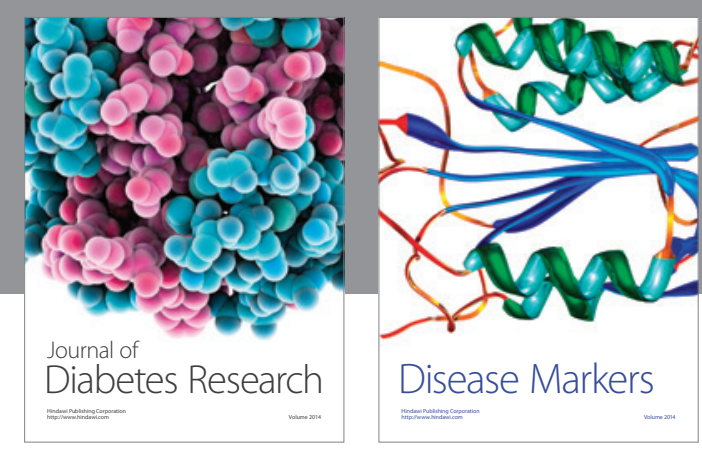

Disease Markers
